\title{
From dermatomyositis to osteoporosis
}

\author{
Florica SANDRU ${ }^{1,2}$, Ana VALEA ${ }^{3,4}$, Simona Elena ALBU ${ }^{1,5}$, \\ Mihai Cristian DUMITRASCU ${ }^{1,5}$, Mara CARSOTE ${ }^{1,6}$ \\ 1 "Carol Davila" University of Medicine and Pharmacy, Bucharest, Romania \\ ${ }^{2}$ Elias Emergency University Hospital, Bucharest, Romania \\ ${ }^{3}$ Clinical County Hospital, Cluj-Napoca, Romania \\ 4 "Iuliu Hatieganu" University of Medicine and Pharmacy, Cluj-Napoca, Romania \\ ${ }^{5}$ Emergency University Hospital, Bucharest, Romania \\ 6 "C.I. Parhon" National Institute of Endocrinology, Bucharest, Romania
}

\begin{abstract}
Our aim is to describe a case of a menopausal woman who started with dermatomyositis and then became a patient at endocrinology because of complicated glucocorticoid osteoporosis. This is a 63-year old female who suddenly started to accuse intense muscle pain associated with redness of the skin. She was confirmed with dermatomyositis and offered high doses of oral metilprednisolone. The thyroid ultrasound showed micronodular background and a small nodule of $0.7 \mathrm{~cm}$ without clinical relevance with an increase of antibodies thyroperoxidase antibody and normal thyroid function. Bone turnover markers were within normal in addition to decrease of serum 25-hydroxyvitamin D of $20 \mathrm{ng} / \mathrm{ml}$. DXA (Dual-Energy X-Ray Absorptiometry) showed ostepenia based on a minimum T-score of -2.4 SD. The patient was offered high doses of cholecalciferol 2,000 UI per day and $500 \mathrm{mg}$ of calcium daily in addition to weekly alendronate due to the high risk of fracture because of the glucocorticoid doses. 6 months later she suffered and accidental fall and a hip fracture was confirmed and required surgery. Further on the therapy was switched to zolendronic acid one injection per year. The dermatological and muscle progressively improved thus the doses of corticoids were reduced. As particular observation the presence of autoimmune thyroid condition may increase the risk of a second autoimmune disease like dermatomyositis, also the specific antibodies panel was negative. A multidisciplinary team needs to be involved in associated therapy for dermatomyositis and complications of glucocorticoids use.
\end{abstract}

Keywords: skin, dermatomyositis, glucocorticoid, osteoporosis

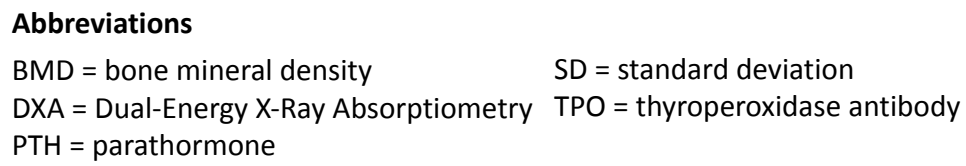

\section{INTRODUCTION}

Some skin conditions require high doses of glucocorticoids as dermatomyositis $(1,2)$. This a coetaneous and muscle inflammatory disease of various causes with heterogeneous clinical and histological aspects $(3,4)$. High doses of glucocorti- coids causes cardio-metabolic and bone complications $(5,6)$.

\section{AIM}

Our aim is to describe a case of a menopausal woman who started with dermatomyositis and 
then became a patient at endocrinology because of complicated glucocorticoid osteoporosis.

\section{MATERIAL AND METHOD}

This is a case report. The clinical and endocrine data are provided.

\section{CASE REPORT}

This is a 63-year old female who is non-smoker and had physiological menopause at age of 50 years. She comes from non-endemic area. Her family history is irrelevant. She associates mild increase of blood pressure which is controlled under anti-hypertensive medication. She suddenly started to accuse intense muscle pain associated with redness of the skin. She was confirmed with dermatomyositis based on muscle enzymes and inflammatory profile but all the immune profile did not conclude a particular cause. So she was offered high doses of oral metilprednisolone.

She was referred for an endocrine check up. The clinical examination was irrelevant for a particular endocrine condition. The thyroid ultrasound showed micronodular background and a small nodule of $0.7 \mathrm{~cm}$ without clinical relevance with a small increase of antibodies thyroperoxidase antibody (TPO) of $70 \mathrm{U} / \mathrm{I}$ with normal levels less than $34 \mathrm{U} / \mathrm{I}$ with normal thyroid function (Figure 1). The screening mammogram did not show any condition (Figure 2 ).

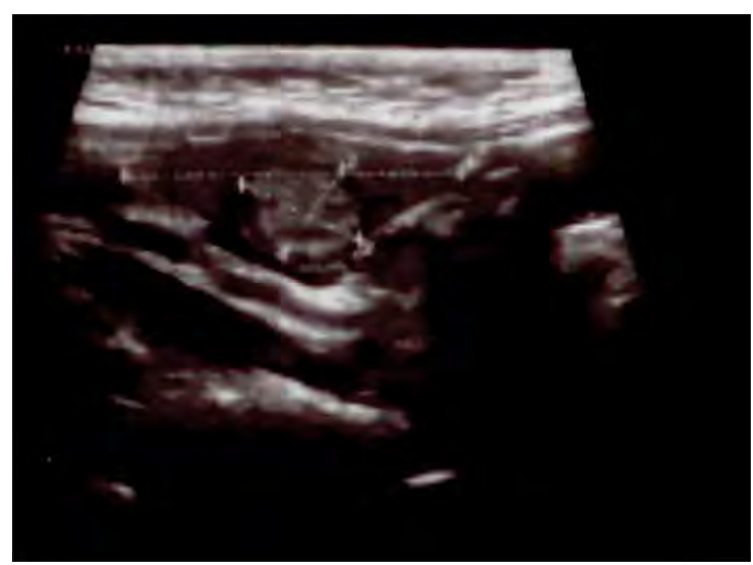

FIGURE 1. Thyroid ultrasound showing a small nodule of $0.7 \mathrm{~cm}$ at adult menopausal woman

Also the bone turnover markers were within normal limits as well as PTH (parathormone) and a small decrease of serum 25-hydroxyvitamin D of $20 \mathrm{ng} / \mathrm{ml}$ was identified. Central DXA (Dual-Energy X-Ray Absorptiometry) showed ostepenia based on BMD (Bone Mineral Density) values according

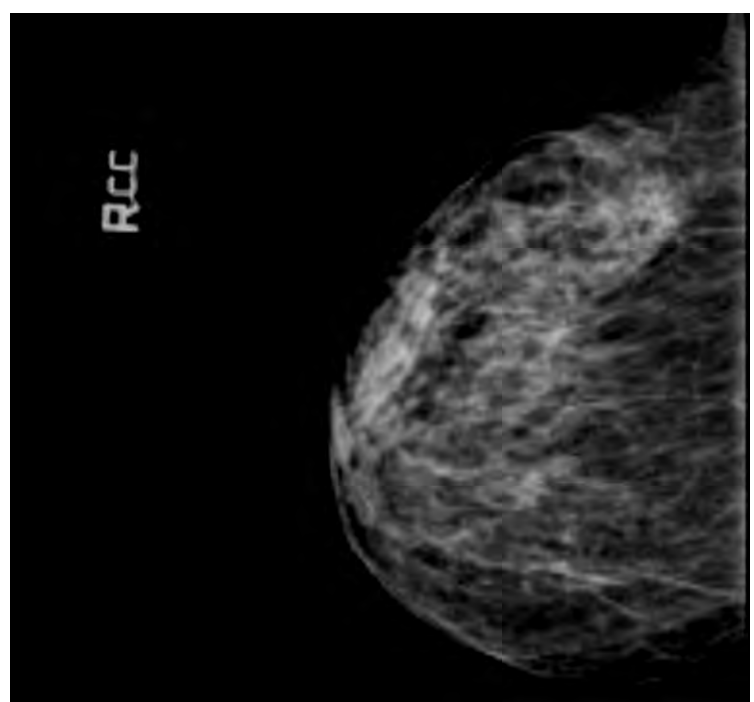

FIGURE 2. Screening mammogram on menopausal female with dermatomyositis of unknown cause (no malignancy was suspected)

to a minimum T-score of -2.4 SD (Figure 3 ). The screening of the vertebral fractures based on profile $X$-ay of the spine showed no lesion. A paraneoplasic syndrome was not confirmed, neither a potential tumour at computed tomography at the level of thorax and abdomen.

The patient was offered high doses of cholecalciferol 2,000 UI per day and 500 mg of calcium daily in addition to weekly alendronate due to the high risk of fracture because of the glucocorticoid doses. 6 months later she suffered and accidental fall and a hip fracture was confirmed and required surgery. Further on the therapy was switched to zolendronic acid one injection per year. The dermatological and muscle progressively improved thus the doses of corticoids were reduced.

\section{DISCUSSION}

In dermatomyositis typically the inflammatory pain and weakness is proximal and symmetrical and once the diagnosis is established corticotherapy and immunosupresive drugs are useful $(1,2,3,4)$. Beyond muscle, skin is also involved as well as lungs and joints (polymyositis type) $(1,2,3,4)$. A particular aspects of skin involvement in dermatomyositis is the synchronous rash with muscle involvement as seen in this case $(1,2,3,4)$. The causes of dermatomyositis are autoimmune or cancer-related but sometimes as in mentioned case they remain as "idiopathic" $(1,2,3,4)$. In this particular situation we avoid the use of an osteoanabolic drug as teriparatide for complicate glucocorticoid osteoporosis since an active neoplasia was not entirely excluded $(7,8)$. 


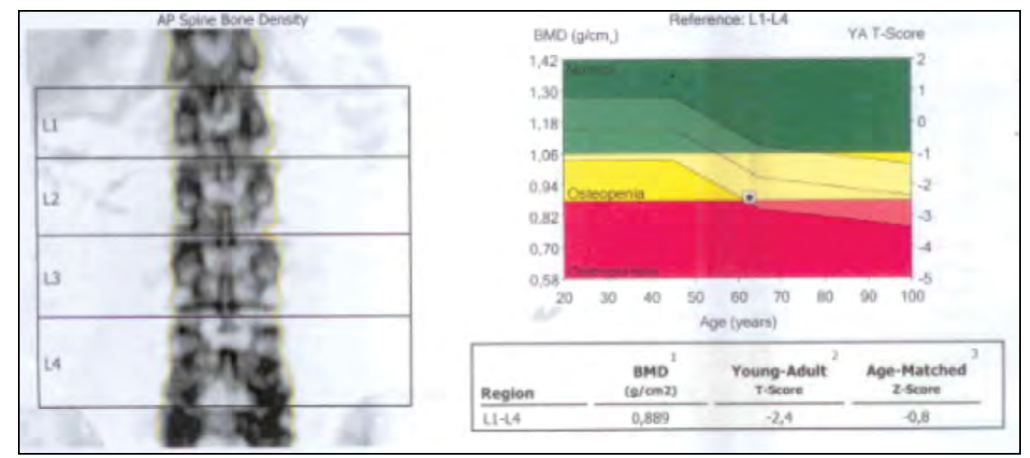

\begin{tabular}{|c|c|c|c|c|c|c|c|c|c|}
\hline Reveson & 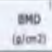 & roms & & & intodent & $\begin{array}{l}\text { BNC } \\
W\end{array}$ & $\begin{array}{l}\text { Neti } \\
\text { (iolit) }\end{array}$ & ${ }_{\text {wath }}$ & $\begin{array}{c}\text { Hegpt } \\
\text { indi) }\end{array}$ \\
\hline u & 0.844 & $\pi$ & 2,1 & 43 & 0,5 & 10.16 & $11 / 2$ & 40 & 2,90 \\
\hline 12 & 0,347 & & 29 & $M$ & I, & 11,34 & 13,10 & 4,1 & 1,20 \\
\hline us & OAl & 74 & 2,6 & ati & 40 & $1,3,36$ & $\mathbb{H S}$ & 4,4 & 100 \\
\hline u & 0,930 & $\pi 0$ & 2,2 & $n$ & 0,6 & 16,05 & {$[8,11$} & (4) & 1,7, \\
\hline tod & 0,899 & 76 & 2,5 & 88 & 0.9 & 21,50 & 25,012 & A, & 6,13 \\
\hline th4 & 0.90 & 74 & 2.5 & 间 & 0,9 & 3,87 & 0,006 & 12 & 9,83 \\
\hline bit4 & Q & 15 & 2,4 & 4) & 4,8 & $51,7,7$ & Q中⿰冫丨 & 4 & 1,27 \\
\hline Qud & $0 \times 0$ & $n$ & 2,8 & 80 & 4,2 & $2,7,7$ & $\boldsymbol{x}, 4]$ & (1) & $(6,6)$ \\
\hline 234 & 0,878 & 79 & 2,6 & 昜 & in & A1,77 & 4,56 & is & 10,77 \\
\hline 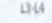 & 0,94 & $7 \pi$ & 2.4 & 97 & 0,8 & 3,2 & 33,16 & 46 & 7.14 \\
\hline
\end{tabular}

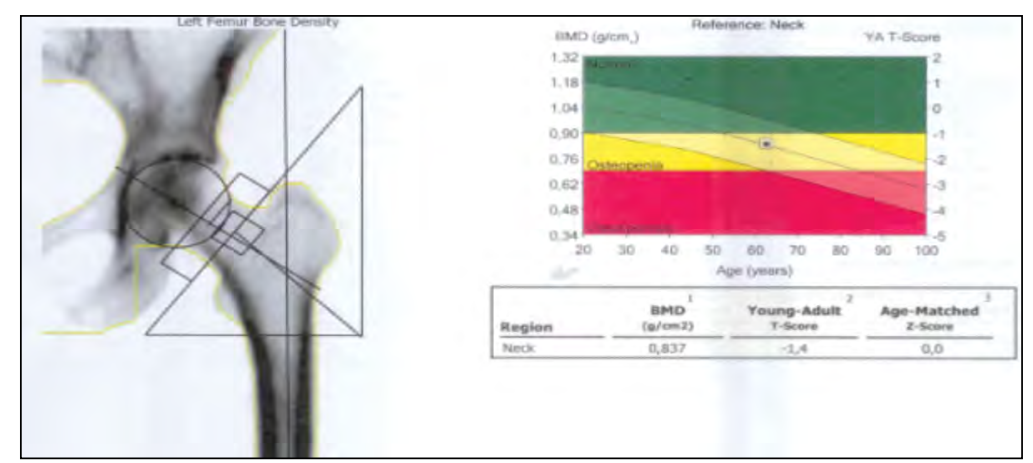

\begin{tabular}{|c|c|c|c|c|c|c|c|}
\hline Region & 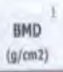 & & & & tatched & $\begin{array}{l}\text { BMC } \\
(0)\end{array}$ & $\begin{array}{l}\text { Avea } \\
\text { (ema) }\end{array}$ \\
\hline hod & 0,837 & 81 & $\cdot 1,4$ & 101 & 0,0 & 3,86 & 4,61 \\
\hline Upper Ned & 0,697 & 85 & 4,0 & 107 & 0,4 & 1,59 & 2,28 \\
\hline lower ved & 0,974 & & - & & . & 2.27 & 2,33 \\
\hline Wors & 0,719 & 79 & 4,5 & 110 & 0,5 & 1,70 & 2,36 \\
\hline Trowh & $0,73 !$ & 86 & 1,0 & 1003 & 0,2 & 9,43 & 12,91 \\
\hline Shat & 1,095 & & & & & 14,84 & 13,56 \\
\hline Tw & 0,905 & 90 & 0,0 & 106 & 0,4 & 28,13 & 31,07 \\
\hline
\end{tabular}

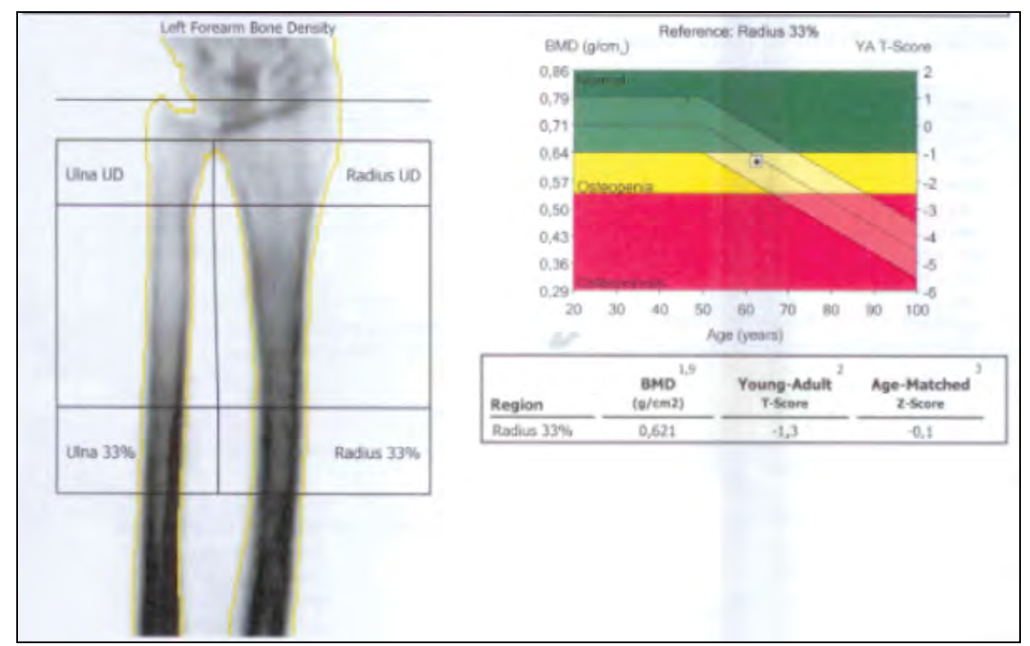

\begin{tabular}{|c|c|c|c|c|c|c|}
\hline Reglon & $\begin{array}{l}\text { BMO" } \\
\text { (q)(mal) }\end{array}$ & $\begin{array}{l}\text { Young-Houth } \\
\text { (3) } 1 \text { seors }\end{array}$ & $\begin{array}{l}\text { lage-Mal } \\
\text { (viv) } 2\end{array}$ & atched & $\begin{array}{l}\text { BMC } \\
\text { (a) }\end{array}$ & $\begin{array}{l}\text { Ares } \\
(\mathrm{m})\end{array}$ \\
\hline Radilus lio & 0,300 & $80 \quad 2,1$ & 90 & 1,0 & 1,00 & 3,63 \\
\hline Und UD & 0,236 & . . & & & 0,45 & 1.88 \\
\hline Redus $33 \%$ & 0,621 & $87.1,3$ & 98 & 0.01 & 146 & 326 \\
\hline
\end{tabular}

FIGURE 3. Osteopenia at central DXA in menopausal woman at the beginning of glucocorticoid therapy for a dermatological autoimmune condition

As particular observation the presence of autoimmune thyroid condition may increase the risk of a second autoimmune disease like dermatomyositis also the specific antibodies panel was negative. However, chronic Hashimoto thyroiditis has a an increased prevalence in general population being considered the most frequent autoimmune condition which may be related to other endocrine and non-endocrine disorders (poly-glandular autoimmune syndrome) or it may be overlapped with other diseases with a high prevalence in general female adult population like metabolic complications including obesity or mammary cancer $(9,10,11)$.
The mentioned subject developed glucocorticoid induced osteoporosis, not the entire picture of iatrogenic Cushing's syndrome while she was priory hypertensive $(12,13)$. Interestingly, some studies pointed that, independently of glucocorticoid iatrogenic exposure or immunosuppressive therapy, in dermatomyositis (as seen in polymyositis) there is a high risk of bone loss and osteoporotic fractures $(14,15)$. A population-based study of cohort type showed that persons with dermatomyositis and polymyositis have a 2.99 time higher risk of osteoporosis than the subjects without this diagnosis (15). Another contributor to fall is hypovitaminosis $D$ with a a high prevalence in general 
population including in menopausal women (16). This is less likely to be related with DXA result at the therapy start and also, based on the therapy with cholecalciferol which was offered to the patient, is not a major contributor to fall at values above $20 \mathrm{ng} / \mathrm{mL}$ as seen here $(17,18)$. Generally a patient under anti-osteoporotic medication may be non-responder in cases with very low levels of vitamin D (19). But in our case the levels of 25-hydroxyvitamin $\mathrm{D}$ was not so low, as contributors to fragility fracture is menopause-related estrogens deficiency, glucocorticoid exposure and the underling dermatological condition itself (20).

\section{CONCLUSION}

A multidisciplinary team needs to be involved in associated therapy for dermatomyositis and complications of glucocorticoids use.

Conflict of interest: none declared Financial support: none declared

\section{REFERENCES}

1. Patsatsi A, Pearson DR, Werth VP. Dermatomyositis in patients with autoimmune blistering diseases. Int $\mathrm{J}$ Womens Dermatol. 2019 Jun 4; 5(4):256-260.

2. Glaubitz S, Schmidt K, Zschüntzsch J, Schmidt $\mathrm{J}$ Myalgia in myositis and myopathies. Best Pract Res Clin Rheumatol. 2019 Jun; 33(3):101433.

3. Strowd LC, Jorizzo JL. Review of dermatomyositis: Establishing the diagnosis and treatment algorithm. J Dermatolog Treat. 2013 Dec;24(6):418-21.

4. Findlay AR, Goyal NA, Mozaffar T. An overview of polymyositis and dermatomyositis. Muscle Nerve. 2015 May; 51(5):638-56.

5. Poiana C, V.Radoi, Carsote M, Bilezekian J. New Clues that May Link Osteoporosis to the Circulating Lipid Profile. Bone Research 2013; 1(3):260-266.

6. Radu L, Carsote M, GheorghisanGalateanu AA, Preda SA, Calborean V, Stanescu R, Gheorman V, Albulescu DM. Blood Parathyrin and Mineral Metabolism Dynamics. A clinical analyze. Rev.Chim. (Bucharest). 2018;69(10):2754-2758.

7. Radu L, Carsote M, Predescu AM, Cojan TS, Socea B, Baleanu VD, Popescu M, Ionovici N, Albulescu DM. Biochemical Parameters in Patients Using Teriparatide. Rev. Chim. (Bucharest). 2018; 69(12):3483-3485.

8. Carsote M, Ghemigian A, Radu O, Valea A. Teriparatide as option for severe osteoporosis. Journal of Medical Practice. 2016; 4(47)-11:324-330.

9. Valea A, Carsote M, Morar A, Mihalca D, Tarau R, Marcusanu A, Talpasanu A, Chereji A, Georgescu CE. High cardiometabolic risk parameters: A crosssectional study in 80 women and men diagnosed with chronic thyroiditis (an age decades analysis). Current Health Sciences Journal. 2015.41(Suppl.1):101-104.

10. Valea A, Carsote M, Moldovan C, Georgescu C. Chronic autoimmune thyroiditis and obesity. Archives of the Balkan Medical Union. 2018;53(1):64-69.

11. Valea A, Ghervan C, Morar A, Pop DD, Carsote M, Albu SE, Georgescu CE, Chiorean A. Hashimoto's thyroiditis and breast cancer: Coincidence or correlation? Archives of Balkan Medical Union. 2016; 51(1):129-132.

12. Buckley L, Humphrey MB. GlucocorticoidInduced Osteoporosis. N Engl J Med. 2018 Dec 27;379(26):2547-2556.

13. Trifanescu $R$, Carsote $M$, Caragheorgheopol A, Hortopan D, Dumitrascu A, Dobrescu M, Poiana C. Screening for secondary endocrine hypertension in young patients. Maedica (Buchar). 2013 Jun;8(2):108-15.

14. Pereira RM, Carvalho JF, Canalis E. Glucocorticoid-induced osteoporosis in rheumatic diseases. Clinics (Sao Paulo). 2010;65(11):1197-205.

15. Lee CW, Muo CH, Liang JA, Sung FC, Hsu $\mathrm{CY}, \mathrm{Kao} \mathrm{CH}$. Increased osteoporosis risk in dermatomyositis or polymyositis independent of the treatments: $A$ population-based cohort study with propensity score. Endocrine. 2016 Apr; 52(1):86-92.

16. Lips $P$, van Schoor NM. The effect of vitamin D on bone and osteoporosis. Best Pract Res Clin Endocrinol Metab. 2011 Aug; 25(4):585-91.

17. Albulescu DM, Carsote M, Ghemigian A, Popescu M, Predescu AM, Tuculina MJ, Bugala AS, Bataiosu M, Marinescu RI, Dascalu IT, Stan M, Cumpata CN, Bechir ES. Circulating 25-hydroxycholecalciferool in relationship to Central Dual-Energy X-Ray Absorptiometry Assesses. A clinical study. Rev.Chim. (Bucharest). 2018; 69(12):3683-3687.

18. Bhattoa HP, Konstantynowicz J, Laszcz N, Wojcik M, Pludowski P. Vitamin D: Musculoskeletal health. Rev Endocr Metab Disord. 2017 Sep;18(3):363-371.

19. Reid IR. Vitamin D Effect on Bone Mineral Density and Fractures. Endocrinol Metab Clin North Am. 2017 Dec; 46(4):935-945.

20. Carsote M, Radu O, Dumitrascu A, Terzea $D$, Valea A, Ghemigian A. Bone and menopause: Threshold of intervention. Romanian Medical Journal. 2016; LXIII(3):233-236. 